\title{
An Effective Exercise for Teaching Cognitive Heuristics
}

\author{
Alan Swinkels \\ St. Edward's University
}

This article describes a brief heuristics demonstration and offers suggestions for personalizing examples of heuristics by making them relevant to students. Students complete a handout asking for 4 judgments illustrative of such heuristics. The decisions are cast in the context of students' daily lives at their particular university. After the professor tallies responses to each question, students discuss their choices and the reasons for them during a subsequent class meeting. Student feedback indicated that this exercise is informative, interesting, and enjoyable. Results from a pretest-posttest study confirmed that student learning improved from before to after the administration of the exercise.

Social perceivers rarely have the luxury of gathering and weighing all the pertinent evidence needed to make a social judgment. Rather, they typically must balance the twin demands of efficiency and accuracy when judging others (Fiske $\&$ Taylor, 1991). Because the social world is a busy place with many elements competing for attention, people must be able to make quick and accurate social judgments. In short, we need to be right, but we also need to be fast when sizing up our social world.

There are several theoretical viewpoints addressing how people perform acts of social perception (for an overview, see Fiske \& Taylor, 1991; Higgins \& Bargh, 1987; Kelley, 1967; Showers \& Cantor, 1985). Among these views, the cognitive miser approach (Taylor, 1981) argues that because people are limited in their capacity to process information, they adopt shortcuts whenever possible. To that end, social perceivers often rely on cognitive heuristics when judging others. Although heuristics help us achieve a balance between efficient social perception and accurate social perception, they can lead us astray. An overreliance on representativeness, availability, simulation, or the anchoring and adjustment heuristic, for example, can lead to conclusions that are incorrect when compared with a more careful, reasoned analysis of the evidence (Kahneman, Slovic, \& Tversky, 1982; Tversky \& Kahneman, 1973, 1974).

Much of the empirical work on heuristics involves presenting research participants with short scenarios calling for social judgments (e.g., asking people to judge the political affiliation of a described person). Although these scenarios clearly capture heuristic reasoning at work, they can be modified to become more personal and memorable for students in a classroom setting. The exercise I describe presents a short, effective demonstration of several heuristics.

\section{Administering the Exercise}

In my social psychology course, I discuss heuristic reasoning during the first 2 weeks of class in the context of person perception, impression formation, and social cognition. At the end of the class meeting on the day before we discuss heuristics, I distribute a handout (see Appendix), telling students that "it's a simple exercise in making judgments about others that will help us discuss our next topic." In the context of the week's material the request seems natural, and students are not aware that the judgments they make will invoke the use of heuristics. The handout takes less than $5 \mathrm{~min}$ to complete. I ask students to write their names on their sheets (so I can return them later) and I collect their responses before class adjourns.

Distributing the handout prior to discussing the topic produces several benefits. First, I can tally students' responses and adapt my presentation based on patterns that emerge. Second, if students catch on to these heuristics at work and try to change their answers during class discussion, I can good-naturedly produce the prior evidence of their written responses. Finally, students are eager to return to class the following day to discover what the exercise illustrates.

\section{Elements of the Exercise}

The handout presents four judgments that illustrate the use of the representativeness, availability, simulation, and anchoring and adjustment heuristics. In each case, relying on a cognitive shortcut produces a less-than-optimal decision.

Representativeness. In making this judgment, students rely on the fact that a description of a specific individual seems to be a good representation of a larger social category (e.g., Rudy's peculiar habits are suggestive of a performer). However, the base rate (i.e., the statistical probability) of any of the other options (e.g., lawyer, surgeon) is substantially higher, making it more likely that the person described holds one of those other occupations. Social perceivers typically ignore the base rate information and are swayed by the seeming representativeness of the description instead (e.g., Kahneman \& Tversky, 1973). 
Availability. This example asks students to judge whether more words in a novel are likely to end in -ing or to have $n$ as the second-to-last letter. The availability heuristic leads students to generate examples of each category to help make their decision. Because examples from one category are more available in memory (running, jumping, flying, skiing, driving, hiking) than are examples from the other (sink, examine, blond), the first case is judged as more likely. However, all -ing endings contain $n$ as the second-to-last letter, making it easy to demonstrate that $n$ endings typically are more likely to occur, despite students' intuitions.

Simulation. This example asks students to judge which of two college roommates would be more upset by being denied permission to enroll in a needed course. Logically, neither student has more cause to be upset. Each student is shut out, both students have to start over, and neither student has much recourse. However, people overwhelmingly judge the student who missed the opportunity by $10 \mathrm{~min}$ to be more upset than the student who missed the opportunity by an entire day. The simulation heuristic relies on the ease of constructing hypothetical scenarios or alternative outcomes. Specifically, because it is easier to imagine ways that a 10-min gap could have been changed rather than a full day's gap, people give the first occurrence more weight in influencing their judgments about emotional reactions to these events. This question is a variation of Kahneman and Tversky's (1982) Mr. Crane and Mr. Tees example. It is more relevant to students because the outcomes are in terms of a college experience that many students have likely encountered.

Anchoring and adjustment. The final example asks students to make a judgment under ambiguous conditions. When faced with this kind of task, most people look for an "anchor" or reference point on which to make their decision and then adjust their final judgment accordingly. However, adjustments are usually insufficient (remaining close to the initial anchor point), and the anchors themselves may not be relevant to the judgment at hand.

For this demonstration, I prepare two versions of the handout. Both are identical, except that half the handouts give a low anchor for this question and the remainder give a high anchor. For example, when asking students to judge how many academic departments are at their university (an ambiguous judgment for which most students have no point of reference) I supply a reasonable low anchor (e.g., 15) on half of the handouts and a reasonable high anchor (e.g., 30) on the other half. Students typically adjust their judgments around the anchor provided on the handout.

\section{Discussing the Exercise}

After students have completed the exercise, I devote the subsequent class meeting to considering heuristics and their pitfalls. After a brief introduction, I return the handouts to the students, and we discuss them for the remainder of the class.

\section{Emergent Patterns}

I have used this exercise successfully in my social psychology, introductory psychology, and cognitive psychology courses during the past 14 years. Almost without exception, the questions lead students to rely on the intended heuristic when making their judgments. For example, students think peculiar cousin Rudy is most likely to be a trapeze artist, although a few savvy students occasionally choose occupations with a higher base rate (e.g., lawyer). Similarly, students generally think Mario is more upset by barely missing his class than Victor, illustrating use of the simulation heuristic. Interestingly, there is often an equal division of students judging the endings of words in a novel. Discrepancies favor the operation of the availability heuristic (i.e., selecting the -ing ending as more common), but perhaps because this judgment is less "social" and presented with a big hint (-ing versus - $\mathrm{n}-$ ), the disparity between judgments is not as great as it is in other cases. This result is in contrast to the anchoring and adjustment example, which clearly shows the operation of that heuristic. When I compute the means of the estimates for each version, it is clear that students rely on the arbitrary anchor provided and that their adjustments remain close to it (e.g., 15.2 and 27.9 when given anchors of 15 and 30).

\section{Student Comments}

When discussing the handout, students often provide "textbook" definitions of the heuristics even as they defend their misbegotten choices. When asked, for example, why Rudy is so likely to be a trapeze artist, at least one student will respond, "Well, he sounds like he's a trapeze artist," which is the epitome of relying on representativeness. The handful of students who relied on base rate information usually make their case quite persuasively, and all students soon understand the operation of the heuristic. In short, students engage in lively discussion over their choices and come to realize that heuristic shortcuts can sometimes falter in comparison to a more reasoned analysis.

\section{Evaluating the Effectiveness of the Exercise}

Using scales ranging from 1 (not at all) to 7 (very much), students have rated various aspects of the social psychology course at the end of each semester over the past several years. Students invariably rate this exercise as being quite effective. Aggregating the mean ratings for each question across seven sections of the social psychology course (total $N=198$ ), students agreed that (a) the presentation helped them understand related text and lecture material $(M=5.84)$; (b) it was informative $(M=5.87)$, interesting $(M=5.72)$, and enjoyable $(M=5.62)$; and $(c)$ the exercise should be retained in future sections of the course $(M=5.87)$. In every case the aggregated average rating is significantly different from 4 , the neutral midpoint of the rating scale (all one-sample $t$ tests significant at $p<.01$, one-tailed). 
Thirty-five students ( 24 women, 11 men) enrolled in introductory psychology $(n=22)$ and social psychology $(n=$ 13) courses during the Spring 2001 semester completed an identical pretest and posttest to assess the effectiveness of the exercise. I administered the pretest a week before the exercise and the posttest a week after the exercise. Both measures presented eight definitions of social behaviors and students selected which of 12 available terms described each one. I embedded the four target heuristics (representativeness, availability heuristic, simulation heuristic, anchoring and adjustment) among four filler items (self-verification, conjunction fallacy, false consensus effect, primacy effect) in the set of definitions. The list of available terms also included fundamental attribution error, belief perseverance, self-fulfilling prophecy, and hindsight bias.

A paired-samples $t$ test comparing the mean number of correct identifications of the four heuristics items on the pretest $(M=1.77, S D=1.19)$ and the posttest $(M=3.26, S D$ $=.82)$ indicated a significant improvement in students' ability to identify these concepts, $t(34)=6.37, p=.0001$ (two-tailed), $\eta^{2}=.54$. An examination of the modes showed that students correctly identified two of the heuristics (50\%) on the pretest and four (100\%) of the heuristics on the posttest. These data suggest that accuracy improved from before to after the presentation of the exercise. However, students were no more accurate on the four filler items on the posttest $(M=1.74, S D=1.12$, mode $=2)$ than they were on the pretest $(M=1.80, S D=.93$, mode $=2), t(34)=.31$, ns. Students in the social psychology course showed a small (M $=3.62, \mathrm{SD}=.65$ ) but significant advantage over students in the introductory psychology course $(M=3.05, S D=.84)$ in the mean number of correct identifications on the posttest, $t(33)=2.09, p=.04$ (two-tailed), $\eta^{2}=.12$.

\section{Conclusions}

This brief exercise is easy to administer, engaging for students, and effective in demonstrating heuristic reasoning. Moreover, it can be used successfully in a variety of courses, such as social psychology, introductory psychology, and cognitive psychology, or any course that considers human reasoning and its limits. Creatively tailoring the details of the exercise to incorporate the experiences of students at their university can make it more engaging.

\section{References}

Fiske, S. T., \& Taylor, S. E. (1991). Social cognition (2nd ed.). New York: McGraw-Hill.

Higgins, E. T., \& Bargh, J. A. (1987). Social cognition and social perception. Annual Review of Psychology, 38, 369-425.

Kahneman, D., Slovic, P., \& Tversky, A. (1982). Judgment under uncertainty: Heuristics and biases. New York: Cambridge University Press.

Kahneman, D., \& Tversky, A. (1973). On the psychology of prediction. Psychological Review, 80, 237-251.

Kahneman, D., \& Tversky, A. (1982). The simulation heuristic. In D. Kahneman, P. Slovic, \& A. Tversky (Eds.), Judgment under un- certainty: Heuristics and biases (pp. 201-208). New York: Cambridge University Press.

Kelley, H. H. (1967). Attribution theory in social psychology. Nebraska Symposium on Motivation, 15, 192-240.

Showers, C., \& Cantor, N. (1985). Social cognition: A look at motivated strategies. Annual Review of Psychology, 36, 275-305.

Taylor, S. E. (1981). The interface of cognitive and social psychology. In J. Harvey (Ed.), Cognition, social behavior, and the environment (pp. 189-211). Hillsdale, NJ: Lawrence Erlbaum Associates, Inc.

Tversky, A., \& Kahneman, D. (1973). Availability: A heuristic for judging frequency and probability. Cognitive Psychology, 5, 207-232.

Tversky, A., \& Kahneman, D. (1974). Judgment under uncertainty: Heuristics and biases. Science, 185, 1124-1131.

\section{Appendix \\ An Exercise in Social Judgment}

1. Dr. Swinkels' cousin, Rudy, is a bit on the peculiar side. He has unusual tastes in movies and art, he is married to a performer, and he has tattoos on various parts of his body. In his spare time Rudy takes yoga classes and likes to collect $78 \mathrm{rpm}$ records. An outgoing and rather boisterous person, he has been known to act on a dare on more than one occasion. What do you think Rudy's occupation most likely is?

A) Farmer B) Librarian C) Trapeze Artist D) Surgeon E) Lawyer

2. In one chapter of a best-selling novel, would you expect to find more words that (circle one)

a) end in -ing (—-ing) OR b) have $n$ as the second to last letter $(-\mathrm{n}-)$ ?

3. Two college roommates, Victor and Mario, are registering for courses for the spring semester. They leave their dorm room together, stop and eat breakfast together, chat with a mutual friend, and arrive at the registrar's office at the same time. They both line up to enroll in their art history classes.

Victor is told the class he wanted was filled to capacity at the end of the previous day.

Mario is told the class he wanted was filled to capacity 10 minutes before he arrived.

Who is more upset, Victor or Mario?

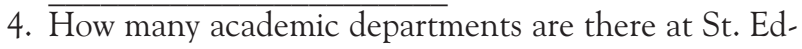
ward's University? (circle one)

a) Fewer than 30 b) More than 30

What is your exact guess? Write a number on this blank line:

\section{Notes}

1. Some of these results were presented at the 21st annual National Institute on the Teaching of Psychology, St. Petersburg Beach, FL, January 1999.

2. I thank Traci A. Giuliano for her helpful comments on earlier drafts of this article.

3. Send correspondence to Alan Swinkels, Department of Psychology, St. Edward's University, 3001 South Congress Avenue, Austin, TX, 78704; e-mail: alans@admin.stedwards.edu. 